\title{
硫化護謨中の硫黄定量に於ける デッカ一氏法に就て
}

昭利 4 年 10 月 15 日鄁演

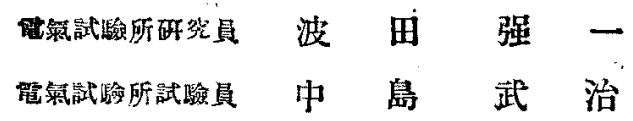

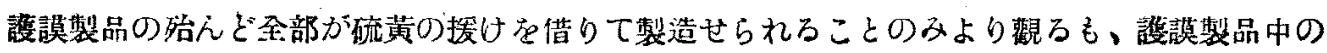

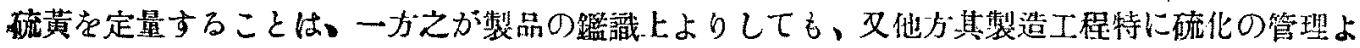
りするも、意莪のおることである。且つ之に加ふに護謨に化合 せられたる硫谨の量は大体に於

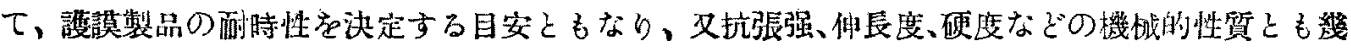
分の關係を辿り得るは可諭、既に本誌上にて報告があつた如く電氣的性質や比重などの物理的性 質とも双脈縕走保持して居万。但し軟質護謨の㙨械的性質と化合硫㣴の關係はエボナイトに見る

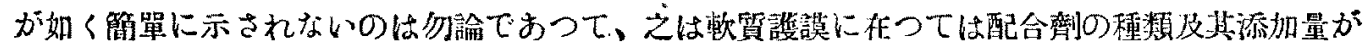
多種多榬なるに原因する。

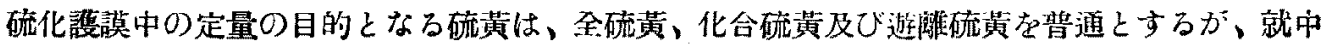
遊離硫黄の定量は簡單で而も常法により无分に正確な結果が得らる〉ものである故、弦所には志 及しない。故にデッカー氏法の價値は全硫黄及化合硫㣴の定量に在るものであるが、其少法も說 明すると次の如くである。

顿質護謨は約 $1 \mathrm{~g}$ を、又ェボナイトは約 $0.2 \mathrm{~g}$ を試料とし正榷に科取し(エボナイトの塲合

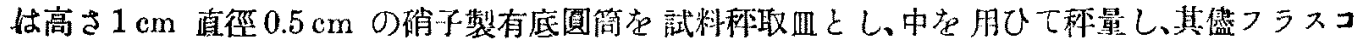
中に投入すれば試料の逸散に因万譟差を荻除し得)、250〜300 c c のメルレンマイヤー・フラスコ

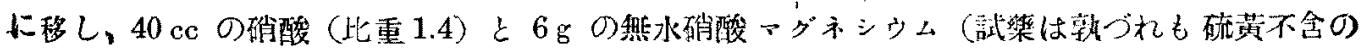

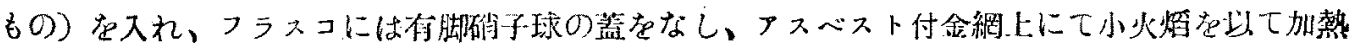

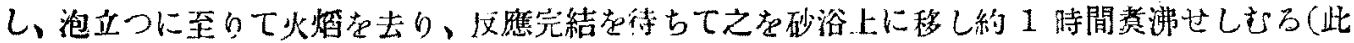

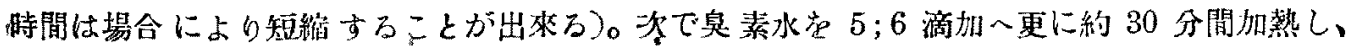

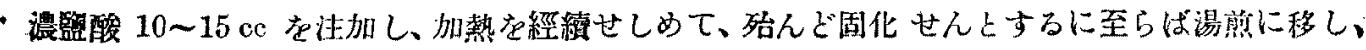
完全に固化せしめ、空氮浴或は砂浴上に加熱し、可溶性硅酸の存在あらば己を不溶性に變じ置き、

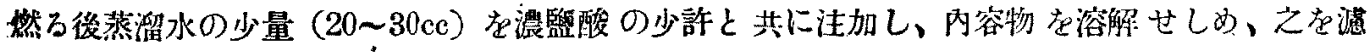

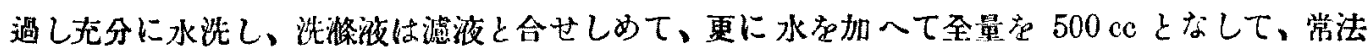

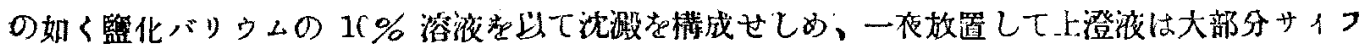




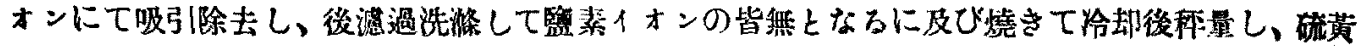
に換睢する。

上下䆩測の結果老揭什て本法の信據に值すべきを示す。

第 1 表

\begin{tabular}{|c|c|c|c|c|c|c|}
\hline 武料潘歌 & 鼠讙灌 & 相 & 年) & 企硫满黒 \% & 毇 & 同上 \% \\
\hline 89 & 93.8 & & 3.2 & 3.307 & +0.17 & +3.3 \\
\hline 119 & 94.2 & & 5.8 & 5.712 & -0.09 & -1.5 \\
\hline 9) & 93.3 & & 6.2 & 6.499 & +0.299 & +4.8 \\
\hline 145 & 92.0 & & 8.0 & 8.020 & +0.021 & +0.5 \\
\hline 134 & 90.0 & & 10.0 & 10.298 & $+0 . \angle 98$ & +3.0 \\
\hline 9 ). & 88.3 & & 11.7 & 11.981 & +0.281 & +2.4 \\
\hline 143 & 87.0 & & 13.9 & 13.012 & +0.021 & +0.1 \\
\hline 88 & 85.0 & & 15.0 & 14.977 & +0.023 & -0.2 \\
\hline 89 & 72.9 & & 17.1 & 17.450 & +0.350 & +0.2 \\
\hline 84 & 71.9 & & 18.1 & 18.123 & +0.023 & +0.1 \\
\hline 85 & 71.0 & & 19.0 & 19.286 & +0.286 & +1.5 \\
\hline 83 & 80.0 & & 20.0 & 19649 & -0.352 & -1.7 \\
\hline 136 & 78.9 & & 22.0 & 21.90 & -0.100 & -0.5 \\
\hline 137 & 76.0 & & 24.0 & 24.519 & +0.519 & +2.2 \\
\hline 138 & 78.7 & & 26.0 & 26.614 & +0.614 & +2.4 \\
\hline 156 & $73 \cdot 0$ & & 27.0 & 27.363 & +0.363 & +1.4 \\
\hline 157 & 71.0 & & 29.0 & 29243 & +0.246 & +0.8 \\
\hline 82 & 69.3 & & 30.9 & $3^{\top} \cdot 714$ & +0.014 & 0.0 \\
\hline 81 & 68.0 & & 32.0 & 32.104 & +0.104 & +0.3 \\
\hline & 66 & & .3 & 3.364 & t & \\
\hline
\end{tabular}

第1圖

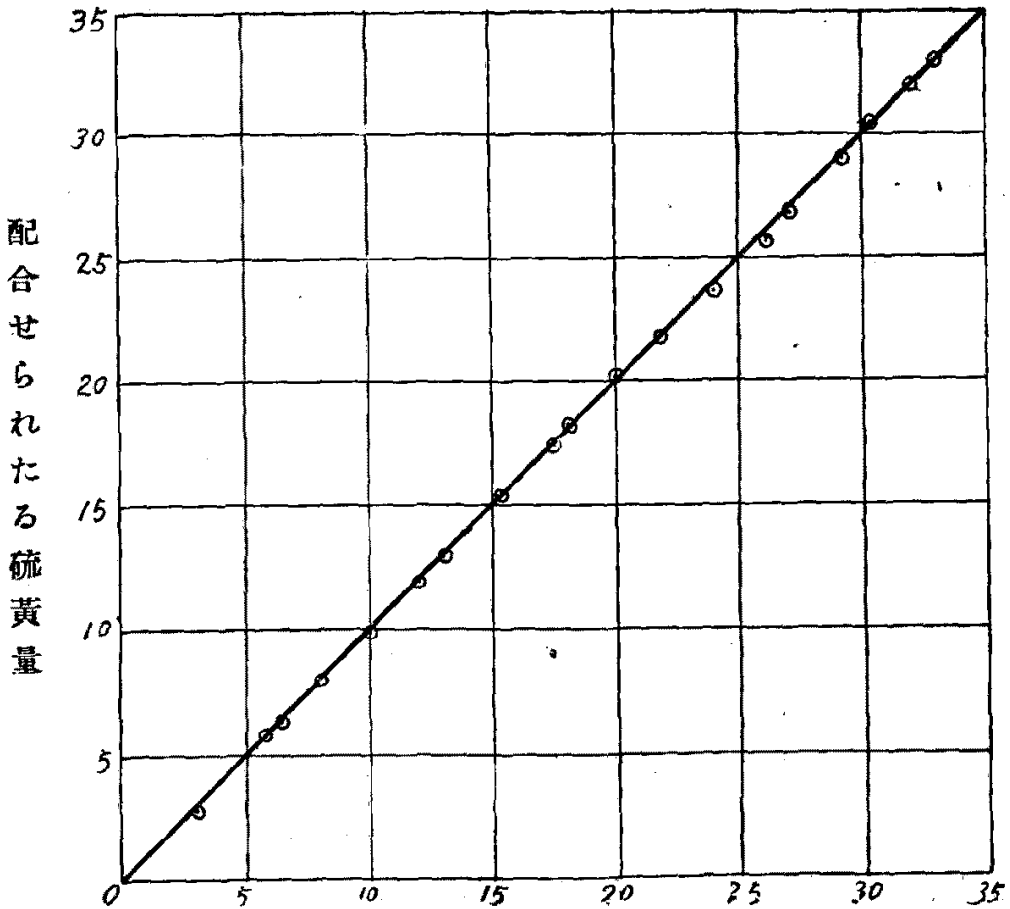

定量せ5れた后硫黄量 
第 2 表

\begin{tabular}{|c|c|c|c|c|c|c|c|}
\hline 斌料番跟 & 護讙 & 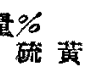 & 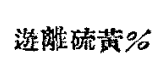 & 化合硫㖆\% & 總硫藏％ & 哭 & 同上\% \\
\hline 89 & 96.8 & 8.2 & 0.034 & 3.210 & 3.248 & +0.048 & +1.5 \\
\hline 90 & 93.8 & 6.2 & 0.080 & 6.228 & 6.308 & +0.108 & +1.7 \\
\hline 91 & 88.3 & 11.7 & 0.157 & 11.544 & 11.701 & +0.001 & 0.0 \\
\hline 88 & 85.0 & 15.0 & 2.031 & 12.930 & 14.961 & -0.039 & -0.3 \\
\hline 87 & 82.9 & 17.1 & 1.466 & 15.823 & 17.289 & +0.189 & +1.1 \\
\hline 86 & 81.0 & 19.0 & 0.250 & 19.373 & 19.623 & +0.623 & +3.3 \\
\hline 86 & 80.0 & 20.0 & 0.254 & 19.633 & 19.883 & -0.117 & -0.6 \\
\hline 82 & 70.0 & 30.0 & 0.720 & 29.988 & 30.708 & +0.708 & +2.3 \\
\hline 81 & 68.0 & 32.0 & 0.885 & 31.039 & 31.924 & -0.075 & -0.2 \\
\hline 83 & 66.7 & 33.3 & 1.961 & 31.464 & 33.425 & +0.125 & +0.4 \\
\hline
\end{tabular}

第 $\quad 2 \quad$ 圖

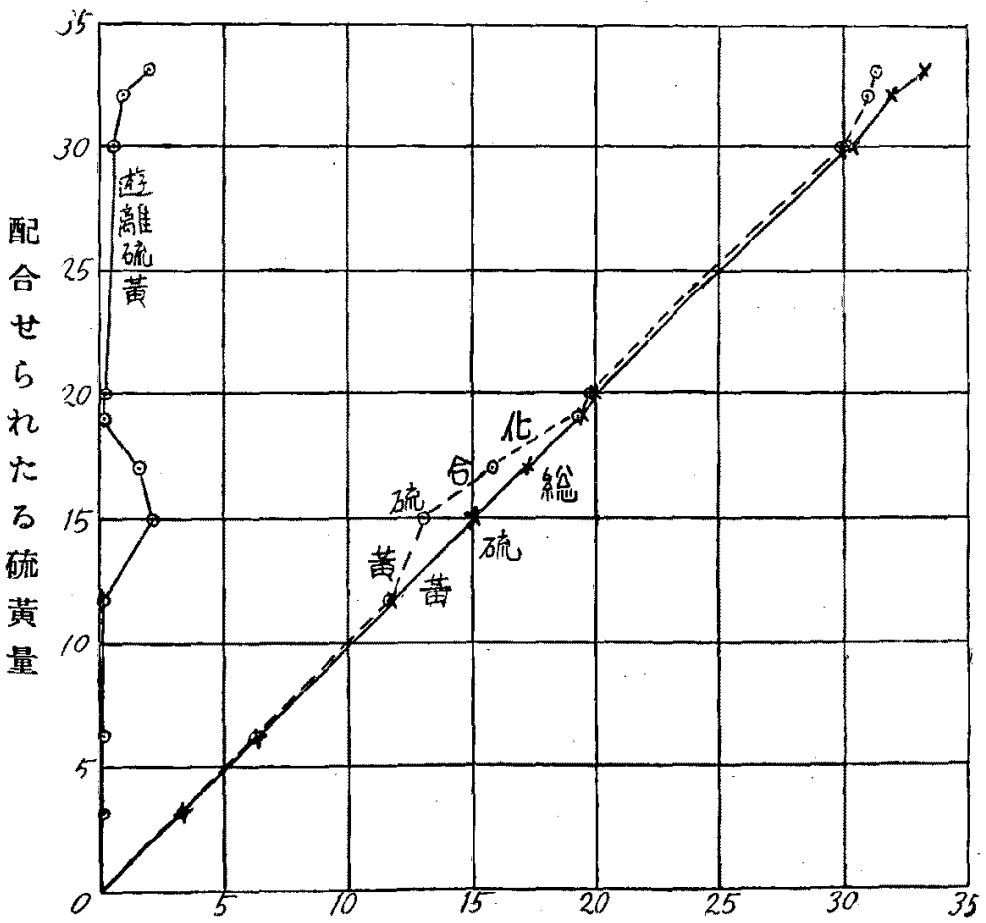

定量せられたら硫黃量

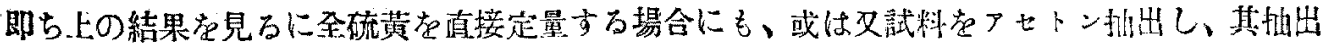

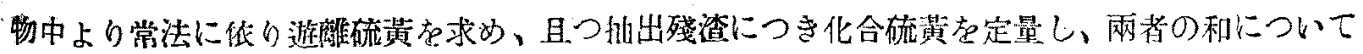
見るも共に本法に相當な正礁性起期待し得るものである。 唒同一試料につき二回定量を重複して行つた結身は次の如くでかる。 
第

\begin{tabular}{ll} 
& 第 1 回測定 \\
& $24.014 \%$ \\
b & 37.272 \\
c & 18.761 \\
& 31.080 \\
\hline & 33.645 \\
f & 21.844 \\
\hline & 21.672 \\
\hline & 22.098
\end{tabular}

第2 四測定
$24.130 \%$
37.140
18.625
31.237
33.402
21.975
21.796
22.075

3

表

今迄に觀察せる本法の测定誤差は人学的操作誤差と同時に試料の不均等性に原因するものなる

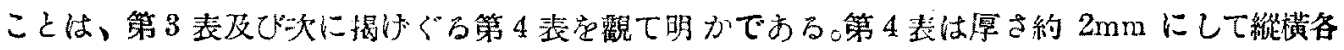
約 $30 \mathrm{~cm}$ なるブレス硫化試料の中央（A）、四隅（B）及じ四隅の中間（C）につき硫橫量党定量

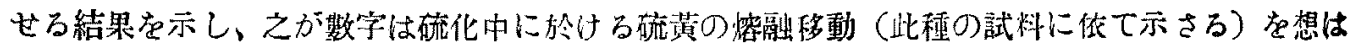
しむるものである（講演に際し明容せる其順位の誏明は之名取消す）。

第 4 表

\begin{tabular}{|c|c|c|c|c|}
\hline 代䈯/武料 & 全硫藏 & 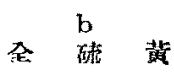 & 化会硣喵 & $\stackrel{c}{c}$ \\
\hline A & $21.901 \%$ & $32.278 \%$ & $20.110 \%$ & $0.091 \%$ \\
\hline$B$ & 22.087 & 33.524 & $2 \smile .451$ & 0.113 \\
\hline C & 21.784 & 33.041 & 20.800 & 0.092 \\
\hline
\end{tabular}

斯くの如き試料に於ける配合劑の分布の不均等は灰分の測定に觀たライネル氏（St. Riner， India Rubber J., 75, 795 （1928））の寞駿に低つても證せらるいが、第 5 表は其結果を引用し

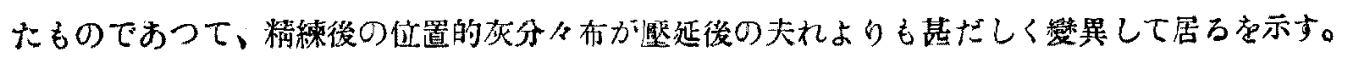

第 $5 \quad$ 表

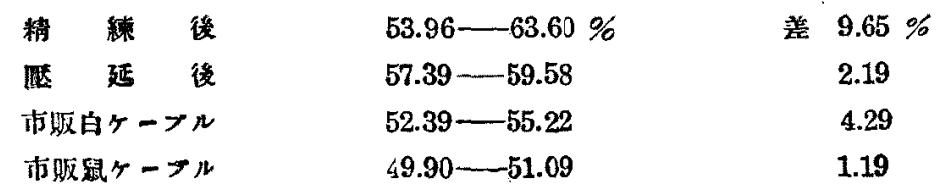

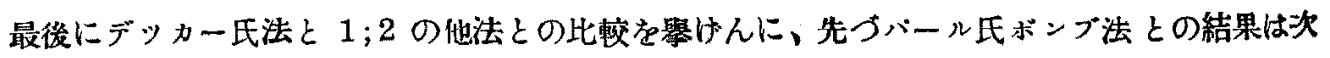
の如くである。因にバ法の項に於て原試料と程したのはデ法と同一試料を用ひた結果にて、籍別

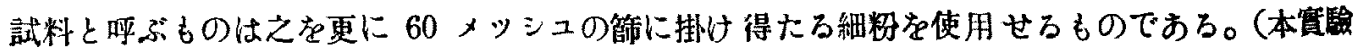

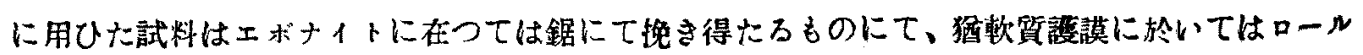
の間は涯潰したる緗粉を使用した)。 


\begin{tabular}{|c|c|c|c|c|c|}
\hline & 第 & 6 & 表 & & \\
\hline 試粼 & デッカー氏法 & 原武数 & $-N$ & 死 & 法 \\
\hline $\mathbf{a}$ & $21.901 \%$ & $15.81 \%$ & & & 18.62 :ó \\
\hline b & 21.734 & 17.46 & & & 20.38 \\
\hline c & 22.037 & 20.58 & & & $21.3 ?$ \\
\hline
\end{tabular}

過酸化曹澾及节性曹達との混合揢融との比较络以下に示すが如くであるが、此場合デッカー氏 法は酸化を 2 時間足らかにて完了せしめしに反し、過酸化曹達法は 7 時閶在要して慎重に酸化 せるちのでおる。

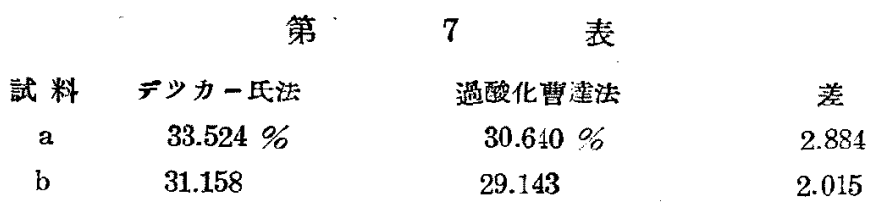

本法は單に護謨中の硫畟の定量に於て迅速且つ信賴すべき結果を西すのみなら亦、石油原油及 石油䳤品などの他種製品にも應周し得るは勿論である。

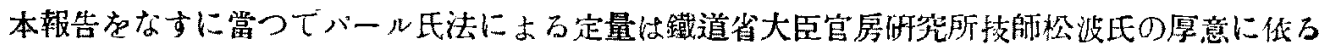
るのでおることを玆所に附記して感謝の意を表する。

正

$\begin{array}{lrl}\text { 頁 } & \text { 枌 } & \text { 誤 } \\ 333 & 1 & 6 \% \\ \text { 同 } & 14 & \text { 以下に } \\ 334 & 10 & \text { クテトン } \\ 335 & 11 & \text { ヒメンマター } \\ \text { 同 } & 14 & \text { 分溜 } \\ \text { 同 } & 19 & \text { 和用 } \\ \text { 同 } & 20 & \text { ヂメチルオクオデン }\end{array}$

遌

IE

$60 \%$

2 以下に

クライン

ピスンマラー

分澄 (分则沈诚)

利用

ギメチルオクタヂン 